\title{
Unexpected Susceptibility of Poly(ethylene furanoate) to UV Irradiation: A Warning Light for Furandicarboxylic Acid?
}

\author{
Evelien Maaskant and Daan S. van Es* \\ Cite This: ACS Macro Lett. 2021, 10, 1616-1621 \\ Read Online
}

\section{ACCESS | Lill Metrics \& More | 回 Article Recommendations | St Supporting Information}

ABSTRACT: Poly(ethylene furanoate) (PEF) is widely advocated as a renewable alternative to the fossil-based polyester poly(ethylene terephthalate) (PET). Whereas the UV stability of PET is well-studied, little is known for PEF. Here, we compare the UV stability of both polyesters after $500 \mathrm{~h}$ of UV irradiation in a QSUN xenon arc chamber. Both the virgin and irradiated polyesters were characterized by FTIR, SEC, DSC, NMR, TGA, and MALDITOF MS. PET showed only minor signs of degradation under the applied test conditions, while PEF showed significant discoloration as well as evidence of both cross linking/chain extension and chain scission. Also, the thermal properties and the ability to crystallize of PEF were severely impacted by UV irradiation. Although a detailed study on the degradation mechanism is out of the scope of this work, we found indications that Norrish type I and II degradation reactions play an important role in the UV degradation of PEF.
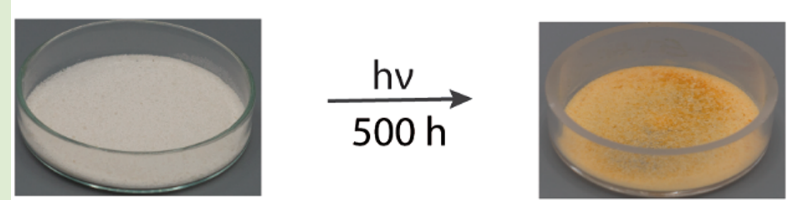

$\mathrm{T}$ he increasing urgency to mitigate greenhouse gas (GHG) emission related climate change and the environmental burden of persistent waste streams has resulted in the desire to have a sustainable circular economy. Plastics in various applications can contribute to a reduced GHG emission and carbon footprint. However, thus far the lack of effective collection and recycling systems has limited the reuse of the carbon atoms in plastics like polyolefins in new, virgin polymers. In contrast, polyesters such as the ubiquitous poly(ethylene terephthalate) (or PET) can be recycled efficiently by chemical depolymerization to its constituent building blocks ethylene glycol (EG) and terephthalic acid (TA). ${ }^{1}$ While this would make PET an ideal circular material, the sustainable production of the building block TA from renewable resources (such as biomass or $\mathrm{CO}_{2}$ ) remains very challenging. In contrast, the renewable TA analogue furan-2,5dicarboxylic acid (FDCA) can already be produced from abundantly available C6 sugars like glucose and fructose on (small) an industrial scale, making this building block a potentially ideal circular alternative to TA. ${ }^{2}$ A vast number of reports over the past decades have shown that FDCA-based polymers, with an emphasis on poly(ethylene furanoate) (PEF), have interesting and industrially relevant properties. ${ }^{3-7}$

Yet, despite the long history of FDCA and its related polymers, some properties have only recently attracted attention. Examples are studies into the toxicity of FDCA and its related diesters, ${ }^{8}$ into the enzymatic hydrolysis of PEF, ${ }^{9}$ or into the (bio)degradability of PEF. ${ }^{10}$ Surprisingly, to the best of our knowledge, we could not find any investigation into the weathering stability of FDCA-based polyesters. On one

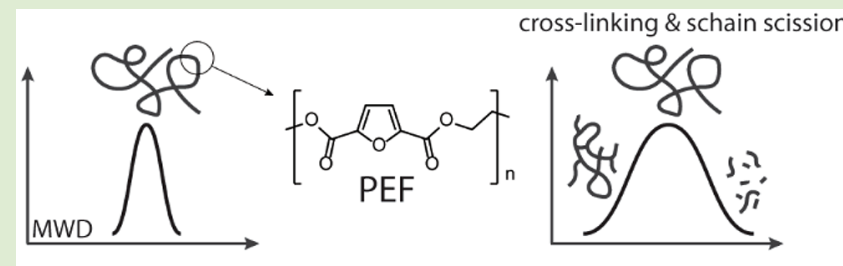

hand, an excellent UV stability will greatly enhance the application window of FDCA-based polymers, but on the other hand, a sensitivity toward UV could enhance the degradation of these materials when emitted into the environment. Here, we present an initial study into the UV stability of PEF, benchmarked against fossil-based PET. Remarkably, we found significant differences in the UV stability of these two polymers, which, in our opinion, could have a detrimental impact on the application scope of FDCA-based polymers.

The UV stability of both reactor grade and precipitated PEF and PET was investigated by irradiating relatively low molecular weight powdery polymeric samples (PEF: numberaverage molecular weight $\left(M_{\mathrm{n}}\right) \sim 6 \mathrm{kDa}$ and PET: $M_{\mathrm{n}} \sim 4$ $\mathrm{kDa}$, particle size $<500 \mu \mathrm{m})$ in a Q-SUN xenon arc chamber for $500 \mathrm{~h}$ at $65{ }^{\circ} \mathrm{C}$ and $60 \mathrm{~W} / \mathrm{m}^{2}$ between 300 and $400 \mathrm{~nm}$. Low molecular weight powders were synthesized, as it was expected that UV-irradiation-induced degradation would be more pronounced due to the high number of end groups and large surface area. It is known that UV degradation of PET is mainly a surface phenomenon, with the most severe degradation occurring in the uppermost $0.5 \mu \mathrm{m}$ after $400 \mathrm{~h}$ of exposure with a xenon arc light source. ${ }^{11}$ Values up to $10-$

Received: November 2, 2021

Accepted: November 29, 2021

Published: December 9, 2021 
a) Poly(ethylene furanoate)

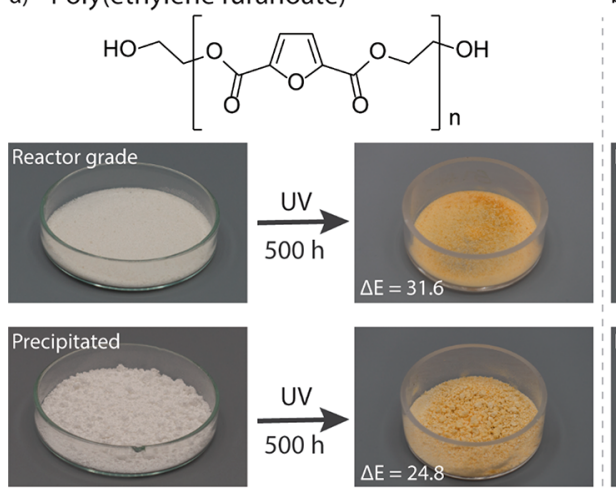

b) Poly(ethylene terephthalate)<smiles>CCC(C)(O)COC(=O)c1ccc(C(=O)OCC(C)(C)O)cc1</smiles>
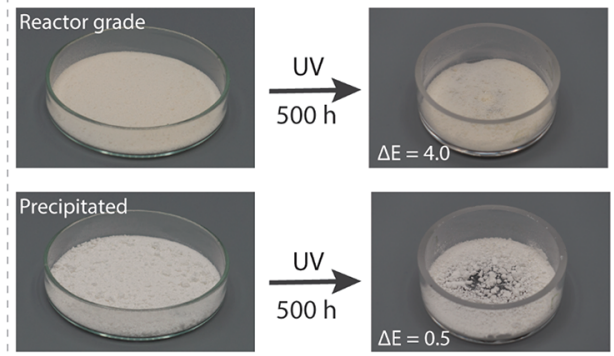

Figure 1. Pictures of (a) PEF and (b) PET before and after UV exposure for $500 \mathrm{~h}$ in the Q-SUN xenon arc chamber. The total color difference $\Delta E$ is calculated from the CieLAB color $L^{*} a^{*} b^{*}$ values according to CIE76.

Table 1. Summary of the Most Important Characteristics of the Polymers before and after UV Exposure ${ }^{a}$

\begin{tabular}{|c|c|c|c|c|c|c|c|c|c|c|}
\hline \multirow[b]{2}{*}{ sample $^{b}$} & \multicolumn{3}{|c|}{ 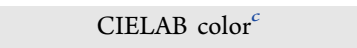 } & \multicolumn{3}{|c|}{ molecular weight ${ }^{d}$} & \multicolumn{4}{|c|}{ thermal properties ${ }^{e}$} \\
\hline & $\Delta L^{*}$ & $\Delta a^{*}$ & $\Delta b^{*}$ & $M_{\mathrm{n}}(\mathrm{kDa})$ & $M_{\mathrm{w}}(\mathrm{kDa})$ & 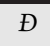 & $T_{\mathrm{g}}\left({ }^{\circ} \mathrm{C}\right)$ & $T_{\mathrm{m}}\left({ }^{\circ} \mathrm{C}\right)$ & $\Delta H_{\mathrm{m}}(\mathrm{J} / \mathrm{g})$ & $\mathrm{Xc}$ \\
\hline PEF-RG-v & - & - & - & 5.9 & 11.5 & 1.9 & 74 & 214 & 47 & 9 \\
\hline PEF-RG-UV & -12.4 & 3.1 & 28.9 & 4.5 & 38.4 & 8.5 & 63 & 199 & 10 & 0 \\
\hline PEF-P-v & - & - & - & 6.3 & 11.5 & 1.8 & 69 & 213 & 45 & 28 \\
\hline PEF-P-UV & -8.8 & 0.6 & 23.2 & $g$ & 19.8 & $g$ & 26 & $h$ & $h$ & $h$ \\
\hline PET-RG-v & - & - & - & 4.1 & 7.6 & 1.9 & 78 & 252 & 57 & 41 \\
\hline PET-RG-UV & 0.7 & -1.4 & 3.6 & 3.7 & 7.6 & 2.0 & 77 & 252 & 54 & 39 \\
\hline PET-P-v & - & - & - & 4.2 & 7.7 & 1.8 & 79 & 250 & 51 & 36 \\
\hline PET-P-UV & 0.2 & -0.4 & 0.3 & 4.1 & 7.8 & 1.9 & 78 & 248 & 54 & 39 \\
\hline
\end{tabular}

${ }^{a}$ The results of the duplicate measurements, and more detailed characterization, can be found in the Supporting Information. ${ }^{b} \mathrm{RG}$ : reactor grade, P: precipitated, v: virgin, UV: after UV irradiation; see Supporting Information for experimental details. ${ }^{c} \mathrm{Change}$ in $L^{*}, a^{*}$, and $b^{*}$ after UV irradiation; absolute values can be found in Table S4. ${ }^{d}$ Determined by size exclusion chromatography (SEC), the value is an average of two measurements. ${ }^{e}$ Determined by differential scanning calorimetry (DSC), data taken from the second heating. ${ }^{f}$ Degree of crystallinity. ${ }^{g} M_{\mathrm{n}}$ could not be calculated accurately. ${ }^{h}$ No melting peak observed.

$20 \mu \mathrm{m}$ after $1600 \mathrm{~h}$ are reported using a high intensity UV weathering facility $\left(170 \mathrm{~W} / \mathrm{m}^{2}\right.$ between 300 and $\left.400 \mathrm{~nm}\right){ }^{12}$ In this study, a xenon arc light source was used to provide a realistic fit with actual solar exposure. The wavelength cutoff of the xenon arc light source is around $295 \mathrm{~nm},{ }^{13}$ whereas the UV absorption of PET has an onset at approximately $310 \mathrm{~nm}$ (Figure S8). This overlap is mentioned as the reason for the photodegradation of several polyesters. ${ }^{14,15} \mathrm{PEF}$, on the other hand, has an onset of UV absorption at approximately $285 \mathrm{~nm}$ (Figure S7), which is outside the range of the xenon arc light source as well as the solar emission profile.

Already after a relatively short exposure time of $500 \mathrm{~h}$ in the Q-Sun chamber, striking differences can be observed between PEF and PET (Figure 1 and Figures S4 and S5), which is also reflected in the CieLAB color $L^{*} a^{*} b^{*}$ values (Tables 1 and S4 and Figure S6). The reactor-grade PEF showed already distinct yellowing after $48 \mathrm{~h}$, which visually intensified over time because more surface area of the particles got exposed after manual mixing. The yellowing is also confirmed by the significant decrease in $L^{*}$ (lightness) and the increase in $a^{*}$ (toward red) and $b^{*}$ (toward yellow) values (Table S4). Interestingly, the PEF discoloration did not visually progress beyond a light brown shade.

The precipitated PEF did not show significant yellowing during the UV irradiation; however, some days after finishing the experiment (the samples were kept in the Q-SUN apparatus at RT and in the dark), a significant yellowing was observed, suggesting that possibly a dark reaction occurred.
Note that all characterizations were performed on the yellowed sample. The $L^{*} a^{*} b^{*}$ color values showed similar development as with the reactor grade PEF, albeit to a smaller extent. Both reactor grade and precipitated PEF became very sticky and showed agglomeration of the particles during and after UV irradiation. In contrast, no visual differences between the virgin and the irradiated material were observed for either reactor grade or precipitated PET. $L^{*} a^{*} b^{*}$ color values showed no significant differences in $L^{*}$ value, while a very minor decrease in $a^{*}$ and an increase in $b^{*}$ were observed, mainly for the reactor grade PET. The small $\Delta E$ values of 4.0 and 0.5 , respectively, confirm the minor color differences of PET upon UV irradiation, whereas PEF displays significantly larger $\Delta E$ values of 31.6 and 24.8 , respectively.

The yellowing and sticky appearance of the PEF after UV exposure indicates that chemical changes to the polymeric structure have occurred. Figure $2 \mathrm{a}$ and $2 \mathrm{~b}$ shows the calculated molecular weight distribution curves for reactor grade and precipitated PEF, respectively. Both show the formation of higher molecular weight species as compared to the virgin material, which is a strong indication for chain extension and/ or cross linking upon UV irradiation. Also, low molecular weight species are formed upon UV irradiation, especially for the precipitated PEF. The $M_{n}$ of the precipitated PEF after UV irradiation could not be calculated accurately because the eluting polymer signal overlaps with the solvent breakthrough signal (Figure S11), most likely due to unwanted interactions between degraded polymer fragments and the column material. 

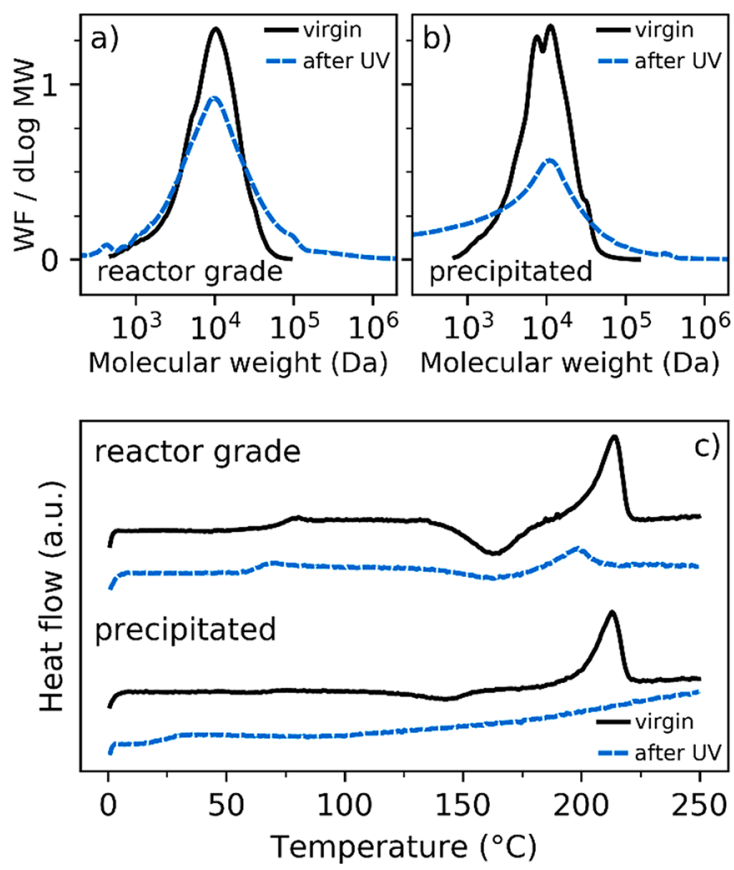

Figure 2. Molecular weight distribution of (a) reactor grade PEF and (b) precipitated PEF before and after UV irradiation. Molecular weight fractions below $100 \mathrm{Da}$ are not shown because we consider them unrealistic. (c) DSC traces (second heating) of the virgin PEF and PEF after UV irradiation.
In contrast to PEF, the PET reference samples showed little to no decrease in molecular weight under the applied test conditions ( $500 \mathrm{~h}$, dry conditions), as shown in Table S5 and Figure S10. Note that other studies that used alternating light only and water spray cycles showed a decrease in the molecular weight of PET already after 100-150 h, and after $500 \mathrm{~h}$ the molecular weight had dropped to $70-80 \%$ of the initial molecular weight. ${ }^{16,17}$ Based on those findings, we expect that PEF will show even more severe degradation under high moisture conditions, but this is part of ongoing research.

In addition, the thermal properties of PEF are severely affected by UV irradiation. Reactor grade PEF shows a minor reduction in glass transition temperature $\left(T_{\mathrm{g}}\right)$ of $\sim 10^{\circ} \mathrm{C}$ and a reduction in melting temperature $\left(T_{\mathrm{m}}\right)$ of $\sim 15{ }^{\circ} \mathrm{C}$. Also the melting enthalpy $\left(\Delta H_{\mathrm{m}}\right)$ of the second heating run has significantly decreased, indicating a decrease in the ability to crystallize. Precipitated PEF shows an even more severe reduction in $T_{\mathrm{g}}\left(\sim 45^{\circ} \mathrm{C}\right)$ and was found to be completely amorphous after the first DSC heating cycle following UV irradiation.

The reduction in $T_{\mathrm{g}}$, decrease in ability to crystallize, and reduction of $M_{n}$ of (mainly the precipitated) PEF can, for example, be related to the presence of low molecular weight degradation products that act as a plasticizer for the polymer matrix. Also, chemical changes to the polymeric structure, such as change in end groups or the formation of hydrophilic groups which increase the polarity and the ability to attract water, can
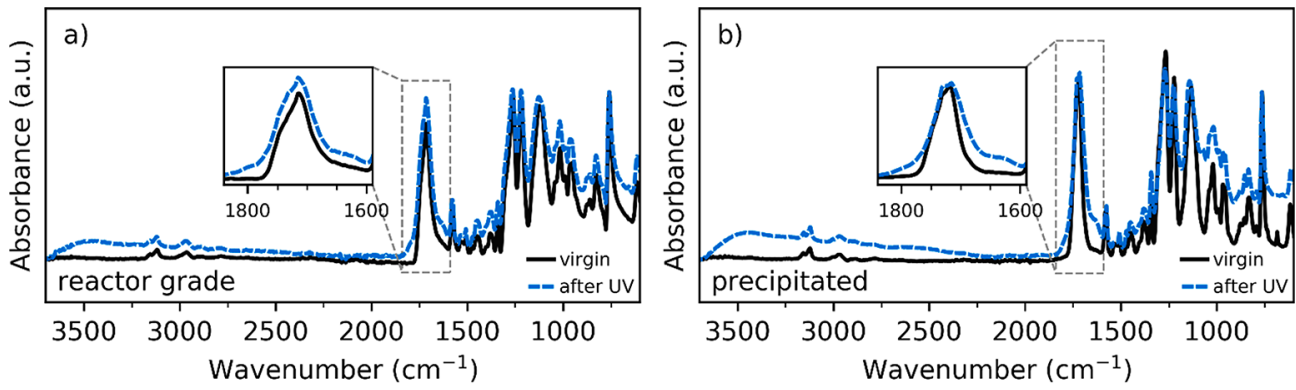

c)
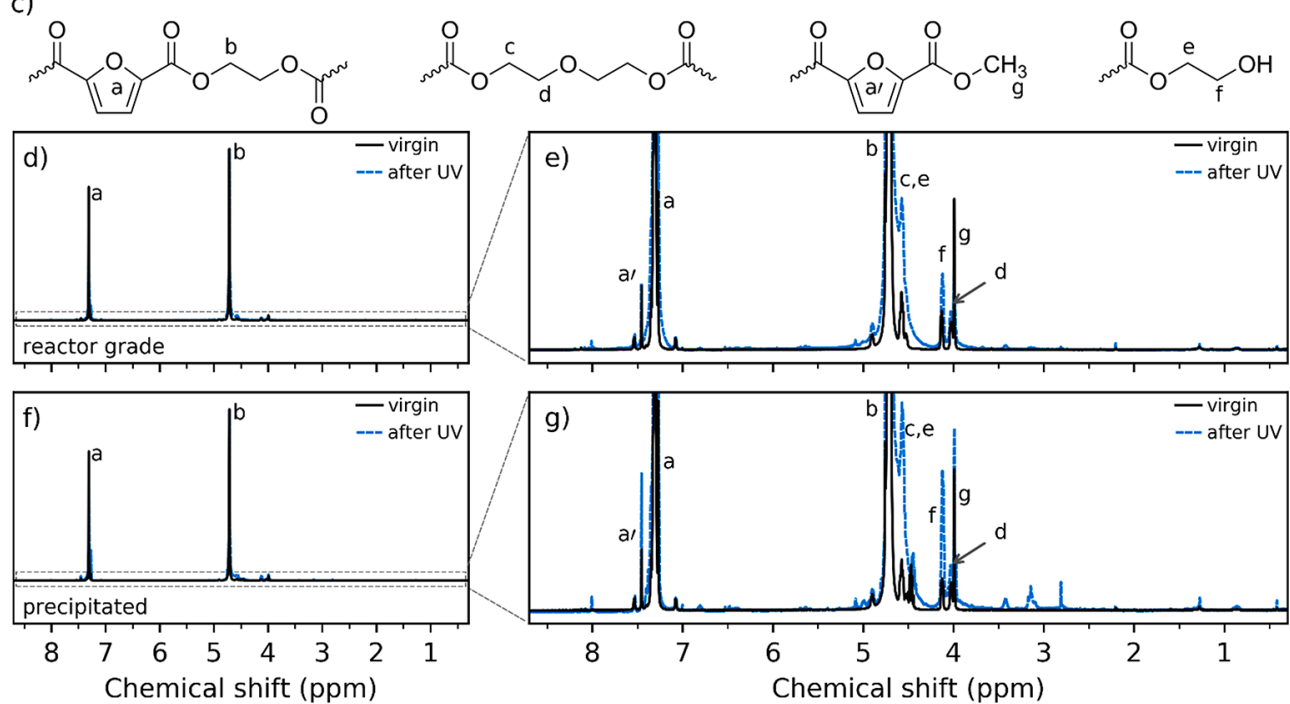

Figure 3. (a,b) ATR-FTIR spectra of reactor grade PEF and precipitated PEF, respectively. All spectra are normalized relative to the absorption at $764 \mathrm{~cm}^{-1}$. (c) Definition of protons in the PEF main chain, diethylene glycol group (DEG), and methyl ester and hydroxyl end groups. (d,f) ${ }^{1} \mathrm{H}$ NMR spectra of reactor grade PEF and precipitated PEF, respectively. (e,g) Zoomed-in spectra of (d) and (f), respectively (enlarged version can be found in Figure S28). All NMR spectra are normalized to the signal at $4.71 \mathrm{ppm}$ (protons b, ethylene glycol). 
have a significant effect on these properties. Although a full chemical characterization of degraded polymers, and hence the chemical pathway of degradation, falls outside the scope of this communication, we have performed some initial characterizations that act as a starting point for more detailed mechanistic studies.

Figure $3 \mathrm{a}$ and $3 \mathrm{~b}$ shows the ATR-FTIR spectra of the reactor grade and precipitated $\mathrm{PEF}$, respectively (full spectra can be found in the Supporting Information). After UV irradiation, a broad signal between 3700 and $2200 \mathrm{~cm}^{-1}$ can be observed, caused by the presence of hydroxyl groups. From the FTIR spectra it cannot be distinguished whether this is caused by either hydroxyl or carboxylic acid (end-) groups or adsorbed water. However, FTIR measurements after extensive drying (Figure S24) and TGA analyses (Figure S17) confirm that both reactor grade and precipitated PEF contain newly formed hydroxyl groups in the chemical structure after UV irradiation.

The carbonyl region in the ATR-FTIR spectra of virgin PEF shows a main absorption at $\sim 1715 \mathrm{~cm}^{-1}$ and a smaller absorption at $\sim 1745 \mathrm{~cm}^{-1}$, which can be attributed to amorphous and crystalline regions in the polymer, respectively. ${ }^{18,19}$ Also a minor shoulder is observed with an absorption maximum at $\sim 1660 \mathrm{~cm}^{-1}$, which is attributed to carboxylic acid groups that can be formed by $\beta$-elimination or ester hydrolysis during the polymer synthesis. After UV irradiation, this right-hand shoulder increases significantly in intensity. In addition, a second shoulder on the left of the main carbonyl absorption (absorption maximum around $\sim 1775$ $\mathrm{cm}^{-1}$ ) is observed, which can be attributed to perester, anhydride, or (aliphatic) aldehyde groups. The formation of shoulders on both the left-hand and right-hand side of the main carbonyl absorption after UV irradiation has also been found for PET and other polyesters. ${ }^{14,15,20-22}$ However, under the applied test conditions $(500 \mathrm{~h})$, we do not find any changes in the ATR-FTIR spectra of PET (Figure S25).

PEF after UV exposure was found to be partially insoluble in common solvents used for dissolving PEF and PET, such as chloroform/trifluoroacetic acid $\left(\mathrm{CHCl}_{3} / \mathrm{TFA}\right)$ (Figure S26). ${ }^{23}$ ${ }^{1} \mathrm{H}$ NMR spectra of the soluble part (in $\mathrm{CDCl}_{3} / \mathrm{TFA}$ ) after UV irradiation are shown in Figure $3 \mathrm{~d}-\mathrm{g}$. These spectra reveal two important differences compared to the virgin material: (1) several very low intensity new signals appear, indicating the formation of protons in a different chemical environment, and (2) the shape and/or integral of the main polymer signals have changed. The signals of the furan and ethylene glycol protons broaden after UV irradiation, which can be explained by the presence of fragments with a wide range in molecular weight or macrostructures (cross linking), and both are in agreement with the GPC data. Another explanation could be anisotropy in the sample due to an increase in viscosity (the TMS signal broadens for some samples as well). The relative integral of the hydroxyl end groups increases upon UV irradiation (Figure S28) for both the reactor grade and precipitated PEF, of which the latter has the highest increase, which is again supporting the apparent chain scission observed in the GPC data. The integrals of the diethylene glycol (DEG) and methyl ester end groups increase slightly as well. All integrals are taken relative to the main furan signal; therefore, this slight increase is attributed to the broadening of the main signals. New ${ }^{1} \mathrm{H}$ signals are detected in the aliphatic region $(<3.5 \mathrm{ppm})$, as well as in the aromatic region $(6.5-8.0 \mathrm{ppm})$. The protons at 8.0 ppm could originate from a 2 -substituted furan ring; a reaction product from Norrish type 1 degradation (Scheme S1). In contrast, the ${ }^{1} \mathrm{H}$ NMR spectra of PET show no significant broadening, and also very few new signals with extremely low intensities are observed after UV irradiation (Figure S32). An increase in hydroxyl end groups is also observed, mainly for the precipitated PEF, in MALDI-TOF analysis (Figure S35 and Table S12). Moreover, a new fragment is found, which corresponds to an end group mass of $m / z$ 93. Also the signal of end group mass $m / z 17$, assigned to carboxylic acid/hydroxyl end groups, increases upon UV irradiation, which is in agreement with the ATR-FTIR spectra.

Next to the striking differences between PET and PEF during UV irradiation under the relatively mild applied conditions ( $500 \mathrm{~h}$, no moisture), the differences between reactor grade and precipitated $\mathrm{PEF}$ are remarkable. A comparison shows that the precipitated PEF is significantly more affected by UV irradiation. As both PEF samples have a similar molecular weight, this is not likely to play a role. The type of end groups, on the other hand, can differ, but the effect of this is part of ongoing research. Another possible explanation can be found in the removal of the titanium isopropoxide catalyst by precipitation. Slow hydrolysis of this catalyst could lead to the formation of photochemically active titanium dioxide $\left(\mathrm{TiO}_{2}\right)$ species. $^{24,25}$ Note that for PET addition of $\mathrm{TiO}_{2}$ has also been shown to have a beneficial effect on weathering stability. ${ }^{26-28}$ It is widely believed that polymer dissolution/precipitation results in removal of the polymerization catalyst, and as such it was expected that the precipitated PEF would be virtually free of residual titanium species. However, ICP-MS analyses showed that there is no significant difference in titanium concentration between the reactor grade and precipitated PEF and PET (Table S3), and thus an effect of residual titanium is unlikely. Furthermore, the PEF contained three times less titanium as PET while showing more severe degradation. Precipitation affects the crystallinity of the virgin polymer, which could explain the differences between reactor grade and precipitated PEF $\left(\chi_{c}=9\right.$ or $28 \%$, respectively). Amorphous regions are more prone to UV degradation; however, it is known for PET that chain scission can also occur in the crystalline regions. ${ }^{29}$ A more detailed study to show the effect of crystallinity in combination with the effect of molecular weight and type of end groups for PEF will be part of our ongoing investigations.

In summary, the present study reports on the UV stability of PEF, compared to the benchmark PET. Remarkable differences are found, where PEF shows significant signs of degradation (e.g., discoloration, chain scission and cross linking, reduction of $T_{\mathrm{g}}$, and ability to crystallize), whereas PET remains more or less unaffected under the applied mild weathering conditions. A more in-depth study on the degradation mechanisms and the factors causing degradation is part of ongoing investigations.

\section{ASSOCIATED CONTENT}

\section{(s) Supporting Information}

The Supporting Information is available free of charge at https://pubs.acs.org/doi/10.1021/acsmacrolett.1c00676.

Experimental details, ICP-MS, color measurements, UV-vis, SEC, DSC, TGA, ATR-FTIR, NMR, and MALDI-TOF data (PDF) 


\section{AUTHOR INFORMATION}

\section{Corresponding Author}

Daan S. van Es - Wageningen Food and Biobased Research, Wageningen University and Research, 6700 AA Wageningen, The Netherlands; Email: daan.vanes@wur.nl

\section{Author \\ Evelien Maaskant - Wageningen Food and Biobased Research, Wageningen University and Research, $6700 \mathrm{AA}$ Wageningen, The Netherlands; $\odot$ orcid.org/0000-0003- 4691-7538}

Complete contact information is available at: https://pubs.acs.org/10.1021/acsmacrolett.1c00676

\section{Author Contributions}

The manuscript was written through contributions of all authors. All authors have given approval to the final version of the manuscript.

\section{Notes}

The authors declare no competing financial interest.

\section{ACKNOWLEDGMENTS}

This research was financed by TKI funding from the Topconsortia for Knowledge \& Innovation (TKI's) of the Ministry of Agriculture in The Netherlands and the companies Archer Daniels Midland Company (ADM) and Evonik. The authors thank Hanneke Brust for performing ICP-MS measurements, Rosalie van de Geest-Sterenborg for her assistance with SEC, TGA, ATR-FTIR, and NMR analyses, Ben van den Broek for performing MALDI-TOF analysis, and Wouter Teunissen for having valuable discussions on the SEC data.

\section{REFERENCES}

(1) Payne, J.; Jones, M. D. The Chemical Recycling of Polyesters for a Circular Plastics Economy: Challenges and Emerging Opportunities. ChemSusChem 2021, 14, 4041.

(2) Skoczinski, P.; Carus, M.; de Guzman, D.; Käb, H.; Chinthapalli, R.; Ravenstijn, J.; Baltus, W.; Raschka, A. Bio-based Building Blocks and Polymers - Global Capacities, Production and Trends 2020-2025; Nova Institute: 2021.

(3) Knoop, R. J. I.; Vogelzang, W.; van Haveren, J.; van Es, D. S. High molecular weight poly(ethylene-2,5-furanoate); critical aspects in synthesis and mechanical property determination. J. Polym. Sci., Part A: Polym. Chem. 2013, 51 (19), 4191-4199.

(4) Thiyagarajan, S.; Vogelzang, W.; Knoop, R.; Frissen, A. E.; van Haveren, J.; van Es, D. S. Biobased furandicarboxylic acids (FDCAs): effects of isomeric substitution on polyester synthesis and properties. Green Chem. 2014, 16 (4), 1957-1966.

(5) van Berkel, J. G.; Guigo, N.; Visser, H. A.; Sbirrazzuoli, N. Chain Structure and Molecular Weight Dependent Mechanics of Poly(ethylene 2,5-furandicarboxylate) Compared to Poly(ethylene terephthalate). Macromolecules 2018, 51 (21), 8539-8549.

(6) Burgess, S. K.; Karvan, O.; Johnson, J. R.; Kriegel, R. M.; Koros, W. J. Oxygen sorption and transport in amorphous poly(ethylene furanoate). Polymer 2014, 55 (18), 4748-4756.

(7) Papageorgiou, G. Z.; Papageorgiou, D. G.; Terzopoulou, Z.; Bikiaris, D. N. Production of bio-based 2,5-furan dicarboxylate polyesters: Recent progress and critical aspects in their synthesis and thermal properties. Eur. Polym. J. 2016, 83, 202-229.

(8) van Vugt-Lussenburg, B. M. A.; van Es, D. S.; Naderman, M.; le Notre, J.; Klis, F. v. d.; Brouwer, A.; van der Burg, B. Endocrine activities of phthalate alternatives; assessing the safety profile of furan dicarboxylic acid esters using a panel of human cell based reporter gene assays. Green Chem. 2020, 22 (6), 1873-1883.
(9) Pellis, A.; Haernvall, K.; Pichler, C. M.; Ghazaryan, G.; Breinbauer, R.; Guebitz, G. M. Enzymatic hydrolysis of poly(ethylene furanoate). J. Biotechnol. 2016, 235, 47-53.

(10) Gruter, G.-J. Technology \& Markets Day Path to the Future. https://www.avantium.com/wp-content/uploads/2019/06/ 20190606-Technology-Day_CTO_Gert-Jan_Gruter_breakout_ final_pdf (accessed June 22, 2021).

(11) Blais, P.; Day, M.; Wiles, D. M. Photochemical degradation of poly(ethylene terephthalate). IV. Surface changes. J. Appl. Polym. Sci. 1973, 17 (6), 1895-1907.

(12) Lin, C.-C.; Krommenhoek, P. J.; Watson, S. S.; Gu, X. Depth profiling of degradation of multilayer photovoltaic backsheets after accelerated laboratory weathering: Cross-sectional Raman imaging. Sol. Energy Mater. Sol. Cells 2016, 144, 289-299.

(13) Q-LAB LX-5060 - A Choice of Filters for Q-SUN. https://www. q-lab.com/documents/public/40a33eb5-8bf9-4501-85d910f0b66aa254.pdf (accessed July 8th, 2021).

(14) Malanowski, P.; Huijser, S.; Scaltro, F.; van Benthem, R. A. T. M.; van der Ven, L. G. J.; Laven, J.; de With, G. Photodegradation of poly(neopentyl terephthalate). Prog. Org. Coat. 2012, 74 (1), 165172.

(15) Malanowski, P.; Huijser, S.; van Benthem, R. A. T. M.; van der Ven, L. G. J.; Laven, J.; de With, G. Photodegradation of poly(neopentyl isophthalate) part I: Laboratory and outdoor conditions. Polym. Degrad. Stab. 2009, 94 (11), 2086-2094.

(16) Fechine, G. J. M.; Souto-Maior, R. M.; Rabello, M. S. Structural changes during photodegradation of poly(ethylene terephthalate). $J$. Mater. Sci. 2002, 37, 4979-4984.

(17) Nguyen-Tri, P.; Prud'homme, R. E. Nanoscale analysis of the photodegradation of polyester fibers by AFM-IR. J. Photochem. Photobiol., A 2019, 371, 196-204.

(18) Forestier, E.; Guigo, N.; Combeaud, C.; Billon, N.; Sbirrazzuoli, N. Conformational Change Analysis of Poly(ethylene 2,5-furandicarboxylate) and Poly(ethylene terephthalate) under Uniaxial Stretching. Macromolecules 2020, 53 (19), 8693-8703.

(19) Araujo, C. F.; Nolasco, M. M.; Ribeiro-Claro, P. J. A.; Rudić, S.; Silvestre, A. J. D.; Vaz, P. D.; Sousa, A. F. Inside PEF: Chain Conformation and Dynamics in Crystalline and Amorphous Domains. Macromolecules 2018, 51 (9), 3515-3526.

(20) Krishnan, S.; Mitra, S. B.; Russell, P. M.; Benz, G., Quantitation of Nonvolatile Components from the Photochemical Decomposition of Poly(ethylene terephthalate). In Polymer Wear and Its Control; American Chemical Society: 1985; Vol. 287, pp 389-401.

(21) Horne, F. J.; Liggat, J. J.; MacDonald, W. A.; Sankey, S. W. Photo-oxidation of poly(ethylene terephthalate) films intended for photovoltaic backsheet. J. Appl. Polym. Sci. 2020, 137 (17), 48623.

(22) Malanowski, P.; Huijser, S.; Scaltro, F.; van Benthem, R. A. T. M.; van der Ven, L. G. J.; Laven, J.; de With, G. Molecular mechanism of photolysis and photooxidation of poly(neopentyl isophthalate). Polymer 2009, 50 (6), 1358-1368.

(23) Dissolving the UV-irradiated PEF in hexafluoroisopropanol (HFIP) resulted in a cloudy solution. The calculated recovery rates in the GPC measurements confirm that the UV-irradiated PEF was also partially insoluble in HFIP.

(24) Fujishima, A.; Rao, T. N.; Tryk, D. A. Titanium dioxide photocatalysis. J. Photochem. Photobiol., C 2000, 1, 1-21.

(25) Lan, Y.; Lu, Y.; Ren, Z. Mini review on photocatalysis of titanium dioxide nanoparticles and their solar applications. Nano Energy 2013, 2 (5), 1031-1045.

(26) Fechine, G.J.M; Rabello, M.S; Souto-Maior, R.M The effect of ultraviolet stabilizers on the photodegradation of poly(ethylene terephthalate). Polym. Degrad. Stab. 2002, 75, 153-159.

(27) Gordon, D. A.; Zhan, Z.; Bruckman, L. S. Characterizing the weathering induced degradation of Poly(ethylene-terephthalate) using PARAFAC modeling of fluorescence spectra. Polym. Degrad. Stab. 2019, 161, 85-94.

(28) Gordon, D. A.; Huang, W. H.; Burns, D. M.; French, R. H.; Bruckman, L. S. Multivariate multiple regression models of poly(ethylene-terephthalate) film degradation under outdoor and multi- 
stressor accelerated weathering exposures. PLoS One 2018, 13 (12), No. e0209016.

(29) Sang, T.; Wallis, C. J.; Hill, G.; Britovsek, G. J. P. Polyethylene terephthalate degradation under natural and accelerated weathering conditions. Eur. Polym. J. 2020, 136, 109873. 